\title{
Ours is a special community
}

\author{
Colin K. L. Phoon \\ Pediatric E Fetal Echocardiography Lab, Division of Pediatric Cardiology, New York University School of Medicine, \\ New York, New York, United States of America
}

Received: 22 November 2014; Accepted: 23 November 2014; First published online: 17 December 2014

$\mathrm{N}$ OT KNOWING WHERE ELSE TO SEND A HEARTFELT message to the Pediatric Cardiology and Congenital Cardiothoracic Surgery community, I thought I would come here, with a personal story.

My cousin, "B", recently contacted me from Australia, seeking my help. He was born with classic d-transposition of the great arteries with intact ventricular septum. My mother used to tell me he was profoundly cyanotic - moribund, really - and was carried everywhere by my maternal aunt on her back. "B" lived in Australia, but after careful research his parents decided to come to the United States of America, to see the renowned John W. Kirklin at the University of Alabama at Birmingham. There, in 1967, "B" underwent Mustard's procedure. He did well: by the time I visited him in 1986, when I was travelling for an international clinical elective at Camperdown Children's Hospital in Sydney, he had graduated with his law degree, was a practicing solicitor, and had married, raising three young children. "B" could outrun me on the tennis court at that time! Over the years, however, I became aware of his rhythm issues and how he would require hospitalisation occasionally.

"B" contacted me recently because he has been experiencing atrial fibrillation/flutter frequently, requiring cardioversion every $2-3$ weeks. He has had seven cardioversions in 8 months, despite taking two potent anti-arrhythmic medications. He underwent a radiofrequency ablation, but his cardiologist was unable to cross the baffle material, and thus could not approach all re-entrant pathways. "B", therefore, sought my help via e-mail: "As a paediatric

Correspondence to: C. K. L. Phoon, MPhil, MD, Associate Professor of Pediatrics and Director, Pediatric \& Fetal Echocardiography Lab, Division of Pediatric Cardiology, New York University School of Medicine, NYU Fink Children's Ambulatory Care Center, 160 East 32nd Street, L-3, New York, NY 10016, United States of America. Tel: 212-263-9990; Fax: 212-263-9678; E-mail: colin.phoon@nyumc.org cardiologist, you will be familiar with my condition and may be able to advise or have contacts who are able to assist in either advising of the material used and/or may have had some experience dealing with arrhythmia in TGA patients and/or locating and obtaining the notes of my heart surgery (I know that it is a long shot but am hopeful that the hospital may have it in their archives). I will be most grateful if you could help me".

I immediately contacted my pediatric electrophysiologist here, Dr Frank Cecchin, who promptly provided advice, and also mentioned he knows pretty much all the paediatric electrophysiologists in Australia. "Can I find out who is doing the procedure?", he asked. In other words, how can he help? I also contacted Dr James Kirklin at University of Alabama at Birmingham, Dr John Kirklin's accomplished son and current Chief of Cardiothoracic Surgery. Dr Kirklin graciously replied within a few hours. Unbelievably, one of his staff unearthed the original operative report and sent along a scanned copy - all in the same day! Within a half day of "B's" original e-mail, I was able to send him the information he needed, and have help at the ready as he continues to struggle with the longterm sequelae of his Mustard palliation.

Ours is indeed a tight-knit global community with a long, rich history of caring for some of the sickest young patients anywhere. Dr Helen Taussig, who nurtured her international relationships in a global network, would have been proud. ${ }^{1}$ From both a professional and personal standpoint, I could not ask for a more special community of colleagues and friends.

Thank you all.

\section{Reference}

1. Neill CA. Dr. Helen Brooke Taussig May 24, 1898-May 21, 1986. International cardiologist. Int J Cardiol 1987; 14: 255-261. 